\title{
Evaluation of Increased Adherence and Cost Savings of an Employer Value-Based Benefits Program Targeting Generic Antihyperlipidemic and Antidiabetic Medications
}

\author{
Bobby Clark, PhD, MSPharm, MHA, MS, MA; Janeen DuChane, PhD, MRP; John Hou, PhD; \\ Elan Rubinstein, PharmD, MPH; Jennifer McMurray, PharmD; \\ and Ian Duncan, FSA, FIA, FCIA, MAAA
}

\begin{abstract}
BACKGROUND: A major employer implemented a change to its employee health benefits program to allow beneficiaries with diabetes or high cholesterol to obtain preselected generic antidiabetic or generic antihyperlipidemic medications with a zero dollar copayment. To receive this benefit, plan beneficiaries were required to participate in a contracted vendor's case management and/or wellness program.
\end{abstract}

OBJECTIVE: To assess changes in medication adherence and the costs for generic antidiabetic and generic antihyperlipidemic medications resulting from participation in a zero copay (ZCP) program.

METHODS: This was a retrospective pre-post comparison group study, evaluating adherence and cost. Participants using an antihyperlipidemic and/or antidiabetic medication during the study identification period and post-implementation period for the program were considered eligible for the study. Eligible beneficiaries who enrolled in the ZCP program during the post-implementation period were considered participants, while those who did not enroll during this period were considered nonparticipants. ZCP program participants and nonparticipants were matched via a 1-to-1 propensity scoring method using age, gender, comorbidity count, medication type (antihyperlipidemic, antidiabetic, or both), and baseline adherence as matching criteria. The proportion of days covered (PDC) metric expressed as a mean percentage was used to assess adherence to medication therapy, while payer cost was examined using prescription drug utilization expressed as per member per year (PMPY) and cost change per 30 days of medication expressed in dollars.

RESULTS: Among participants who were users of antidiabetic medications, the mean adherence rate was sustained from pre- to post-implementation $(81.8 \%$ vs. $81.9 \%)$; however, it decreased in the matched nonparticipant group $(81.9 \%$ vs. $73.1 \%)$. This difference in mean adherence over time between the participants and nonparticipants was statistically significant ( $0.1 \%$ vs. $-8.8 \%, P<0.001)$. Similar results were found among users of antihyperlipidemics. The mean adherence rate was sustained over time for participants $(\mathbf{7 7 . 7} \%$ vs. $\mathbf{7 8 . 3} \%)$ but declined over time for nonparticipants (77.6\% vs. $70.8 \%$ ). The difference in mean change over time was statistically significant between participants and nonparticipants $(0.6 \%$ vs. $-6,8 \%$, $P<0.001)$. Average prescription costs PMPY increased for participants of the ZCP program during the post-implementation period; however, the increase was not larger than the cost increase among nonparticipants ( $\$ 581$ vs. $\$ 584, P=0.95$ ). Furthermore, among antihyperlipidemics the cost increase post-implementation was actually significantly less for participants than nonparticipants ( $\$ 51$ vs. $\$ 143, P<0.001$ ).

CONCLUSIONS: Plan sponsors are increasingly evaluating the use of valuebased benefit design (VBBD) to change member behavior. This ZCP pro- gram used a reduction in cost sharing to incentivize members to use more generic drugs and to enroll in a care management coaching program. The study also demonstrated that a VBBD program can have a positive impact on adherence and cost outcomes among those who participate compared with nonparticipants.

J Manag Care Pharm. 2014;20(2):141-50

Copyright $\odot$ 2014, Academy of Managed Care Pharmacy. All rights reserved.

\section{What is already known about this subject}

- Nonadherence to medication therapy is associated with increased risk for all-cause hospitalization $(\mathrm{OR}=1.58,95 \% \mathrm{CI}=1.38-1.81$, $P<0.001)$ and increased risk for all-cause mortality $(\mathrm{OR}=1.81$, 95\% CI $=1.46-2.23, P<0.001)$

- Copayment reductions are associated with improvements in medication adherence to antidiabetic therapy as measured by the medication possession ratio (MPR), which increased $4.9 \%$ $(P<0.001)$ for the value-based benefit design (VBBD) group and decreased $2.3 \%(P<0.001)$ for the comparison group.

\section{What this study adds}

- Introduction of a VBBD targeting beneficiaries with diabetes and/ or hyperlipidemia using a zero-dollar generic copayment as an incentive for participation can result in a large and statistically significant difference in adherence change over time between participants and nonparticipants of the program. In the antidiabetic and antihyperlipidemic medication groups, program participants exhibited statistically higher absolute mean changes in proportion of days covered from the pre-period to the postperiod compared with the comparison group (antidiabetics: $0.1 \%$ vs. $-8.8 \%, P<0.001$; antihyperlipidemics: $0.6 \%$ vs. $-6.8 \%$, $P<0.001)$. Increased drug utilization and reduced member cost sharing were achieved without increasing the plan sponsor's cost for participants relative to nonparticipants. While average cost PMPY increased during the post-implementation period, it was not larger than the increase among nonparticipants (\$581 vs. $\$ 584, P=0.95$ ). Furthermore, among antihyperlipidemics, the cost increase was actually significantly less among participants than nonparticipants ( $\$ 51$ vs. $\$ 143, P<0.001$ ). 
$\mathrm{V}$ alue-based benefit design (VBBD), also known as valuebased insurance design (VBID), refers to employerbased incentives designed to "encourage enrollee adoption of one or more of the following:

- appropriate use of high-value services, including certain prescription drugs and preventive services;

- adoption of healthy lifestyles, such as smoking cessation or increased physical activity; and

- use of high performance providers who adhere to evidencebased treatment guidelines."

Enrollee incentives can include rewards, reduced premium share, adjustments to deductible and copay levels, and contributions to fund-based plans such as health savings accounts.

The focus of VBBD is on the relationship of beneficiary cost share to the value of, rather than to the cost of, clinical services. ${ }^{2}$ VBBD has been discussed as a way to improve employee health and productivity through enhanced consumer engagement. There is a high level of interest in VBBD among larger employers. ${ }^{3,4}$ A survey conducted in 2010 showed that $14 \%$ of employers with more than 500 employees and $25 \%$ of employers with more than 20,000 employees have implemented VBBD programs. ${ }^{5}$

Nonadherence to medication therapy is a significant problem across chronic disease states. ${ }^{6-8}$ Nonadherence may be driven by myriad factors, including personal, sociodemographic, disease, comorbidity, health status, and cost, as well as beneficiary perception of drug therapy value, factors related to drug regimen complexity and side effects, and poor communication with health professionals. ${ }^{9-13}$ An inverse relationship between copayment and adherence to medication therapy has been documented across beneficiary disease states and severity of illness. ${ }^{14-16}$ A similar relationship has been documented between lower cost sharing for prescription drugs and increased adherence to therapy. ${ }^{17,18}$ In a retrospective cohort study of older adults with employer-sponsored drug coverage, higher copayments for prescription drugs were found to be associated with delayed initiation of therapy. ${ }^{19}$ As an example of VBBD, copayments for prescription drugs could be selectively eliminated to encourage beneficiary adherence to prescribed drug therapy. ${ }^{20,21}$

A positive correlation between nonadherence, adverse outcomes, and medical cost has also been documented. ${ }^{22-25} \mathrm{~A}$ 2003 retrospective cohort study of beneficiaries enrolled in the Kaiser Permanente of Colorado diabetes registry determined that nonadherence to medication therapy was associated with increased risk for all-cause hospitalization as measured by odds ratio $(\mathrm{OR}=1.58,95 \%$ confidence interval $[\mathrm{CI}]=1.38-1.81$; $P<0.001)$ and increased risk for all-cause mortality $(\mathrm{OR}=1.81$, $95 \% \mathrm{CI}=1.46-2.23 ; P<0.001)$. This study found that incremental improvements in medication adherence of at least $25 \%$ were associated with improved outcomes, including reduced systolic and diastolic blood pressure, reductions in hemoglobin
Alc (HbAlc), reductions in low-density lipoprotein cholesterol (LDL-C) levels, reductions in all-cause hospitalization, and reductions in all-cause mortality. ${ }^{26}$

Another study of insured beneficiaries enrolled in a health maintenance organization diagnosed with diabetes, hypercholesterolemia, and hypertension in the period 1999 through 2001 showed a positive correlation between nonadherence and HbAlc and LDL-C levels. ${ }^{27}$ Benefits of higher drug adherence may include improved beneficiary health status, improved worker productivity, reduced medical consequences of disease, and/or avoidance of costly medical interventions, although there is insufficient documentation of these benefits at the present time..$^{28,29}$

A recent pre-post study compared adherence to antidiabetic therapy for continuously eligible plan participants 1 year before and after their pharmacy benefit plan modified its copayment structure to incentivize certain behaviors. Copayments for the generic and insulin therapies dropped from $\$ 15$ to $\$ 0$; copayments for the preferred brands dropped from $\$ 30$ to between $\$ 10$ and $\$ 15$; and copayments for the nonpreferred brands remained at $\$ 35$. This resulted in higher treatment initiation rates $(2.3 \%$ vs. $1.4 \%, P<0.001)$ and lower discontinuation rates for metformin $(\mathrm{OR}=1.7,95 \% \mathrm{CI}=1.2-2.2 ; P<0.01)$, antidiabetic combinations $(\mathrm{OR}=2.5,95 \% \mathrm{CI}=1.5-4.3 ; \mathrm{P}<0.01)$, and insulin $(\mathrm{OR}=1.9,95 \% \mathrm{CI}=1.3-2.9 ; \mathrm{P}<0.01)$ for the VBBD group compared with the comparison group in the year following the benefit design change. Adherence to antidiabetic therapy as measured by the medication possession ratio (MPR) increased 4.9 percentage points $(P<0.001)$ for the VBBD group and decreased 2.3 percentage points $(P<0.001)$ for the comparison group. $^{30}$

This article presents an analysis of a zero copay (ZCP) program implemented in January 2010 for a major employer's employees, dependents, and retirees enrolled in the employee health plan with a diagnosis of diabetes or hyperlipidemia. Using a study design similar to that used in the Chang et al. (2010) study, ${ }^{30}$ the current research effort implements a less dramatic reduction in copayments to ascertain the VBBD program's impact on adherence and cost. Eligibility for the ZCP program was contingent on beneficiary participation in a contracted vendor's case management and/or wellness program. The research objective of this study was to assess the impact on beneficiary adherence and plan sponsor cost of offering generic antidiabetic and antihyperlipidemic medications without cost sharing.

\section{Methods}

\section{Program Description}

A major employer's employee benefits program was changed on January 1, 2010, to allow members to obtain certain generic diabetic and antihyperlipidemic medications with zero copay, provided that the beneficiary participated in a disease management and/or wellness program. This is referred to as the ZCP 
Evaluation of Increased Adherence and Cost Savings of an Employer Value-Based

Benefits Program Targeting Generic Antihyperlipidemic and Antidiabetic Medications

\begin{tabular}{l|l|c|c|l}
\hline TABLE 1 & \multicolumn{1}{c}{ Prescription Drug Plan Copay Rates (2009-2011) } & \multicolumn{1}{c}{ Nonpreferred Brand } \\
\hline Year & & Generic $(\$)$ & Preferred Brand (\$) & $\begin{array}{l}30 \% \text { coinsurance with a minimum } \\
\text { copay of } \$ 47 \text { and a maximum of } \$ 107\end{array}$ \\
\hline \multirow{2}{*}{2009} & Up to 30-day supply & 5.00 & 29.00 & $\begin{array}{l}30 \% \text { coinsurance with a minimum copay of } \$ 117.50 \\
\text { and a maximum of } \$ 267.50\end{array}$ \\
\cline { 2 - 5 } 2010 & 30- to 90-day supply & 12.00 & 30.00 & $\begin{array}{l}30 \% \text { coinsurance with a minimum } \\
\text { copay of } \$ 47 \text { and a maximum of } \$ 107\end{array}$ \\
\hline \multirow{2}{*}{2011} & Up to 30-day supply & 5.00 & 75.00 & $\begin{array}{l}30 \% \text { coinsurance with a minimum copay of } \$ 117.50 \\
\text { and a maximum of } \$ 267.50\end{array}$ \\
\cline { 2 - 5 } & 30- to 90-day supply & 12.00 & 30.00 & $\begin{array}{l}30 \% \text { coinsurance with a minimum } \\
\text { copay of } \$ 47 \text { and a maximum of } \$ 107\end{array}$ \\
\cline { 2 - 5 } & Up to 30-day supply & 5.00 & 75.00 & $\begin{array}{l}30 \% \text { coinsurance with a minimum copay of } \$ 117.50 \\
\text { and a maximum of } \$ 267.50\end{array}$ \\
\cline { 2 - 5 }
\end{tabular}

TABLE 2 Generic Medications Covered by the Zero Copay Program

\begin{tabular}{|c|c|c|c|}
\hline \multicolumn{2}{|c|}{ Antihyperlipdemics } & \multicolumn{2}{|c|}{ Antidiabetics } \\
\hline Generic Name & GPI $10^{\text {a }}$ Code & GPI 10 Code & Generic Name \\
\hline Chlorpropamide & 2720002000 & 3910001000 & Cholestyramine \\
\hline Glimepiride & 2720002700 & 3910001010 & Cholestyramine light \\
\hline Glipizide & 2720003000 & 3910002010 & Colestipol $\mathrm{HCl}$ \\
\hline Glyburide & 2720004000 & 3920002500 & Fenofibrate \\
\hline Glyburide micronized & 2720004010 & 3920003000 & Gemfibrozil \\
\hline Tolazamide & 2720005000 & 3940005000 & Lovastatin \\
\hline Nateglinide & 2723405000 & 3940006510 & Pravastatin sodium \\
\hline Metformin $\mathrm{HCl}$ & 2725005000 & 3940007500 & Simvastatin \\
\hline Acarbose & 2750001000 & & \\
\hline Glipizide-metformin $\mathrm{HCl}$ & 2799700235 & & \\
\hline Glyburide-metformin & 2799700240 & & \\
\hline Metformin HCl-nutritional supplement & 2799900250 & & \\
\hline
\end{tabular}

${ }^{a}$ GPI is Generic Product Identifier, a segmented numeric drug code assigned by Medi-Span, using a hierarchical classification scheme encompassing drug group, class, subclass, name, name extension, and dosage.

program. The employer's plan provided 3 tiers of cost sharing, as shown in Table 1. The ZCP program was designed to incentivize patients to continue using generic drugs (if already a user) or to switch to a generic drug (if a brand user).

Eligible participants included active employees, dependents, and retired plan participants who had coronary artery disease, hyperlipidemia, and/or diabetes and met the terms of enrollment and participation in 1 or more programs, including disease management and wellness programs addressing diabetes, cardiac conditions, weight management, stress management, exercise, and nutrition. Specific drugs covered by the ZCP program are shown in Table 2.

As part of the program, the vendor invites a beneficiary to complete an initial assessment of need and to participate in 1 or more wellness or disease management programs appropriate for the member's condition or lifestyle. If the beneficiary agrees, he or she is flagged in the vendor's database and is considered "enrolled" on acceptance of 1 or more phone calls or interactions with a vendor health coach or nurse and completion of the initial member assessment. Once enrolled, the beneficiary becomes eligible for the ZCP program, and eligibility continues through the benefit year unless the beneficiary drops out of all disease management and wellness programs or cannot be reached for scheduled coaching, after which the beneficiary is terminated from the ZCP program. If the beneficiary is terminated from the program, the member's copay reverts to the plan level.

In granting the organization's request to remain anonymous, we have not included any further information.

\section{Study Design}

This was a retrospective pre-post comparison group study. The study had 3 main time periods: (a) identification period, (b) pre-implementation period, and (c) post-implementation period. A 6-month identification period was used to determine which beneficiaries were taking a medication for treatment of diabetes and/or hyperlipidemia and were existing users. The pre-implementation period was the 18 months after the 


\section{FIGURE 1 Zero Copay Program Study Period Specification}

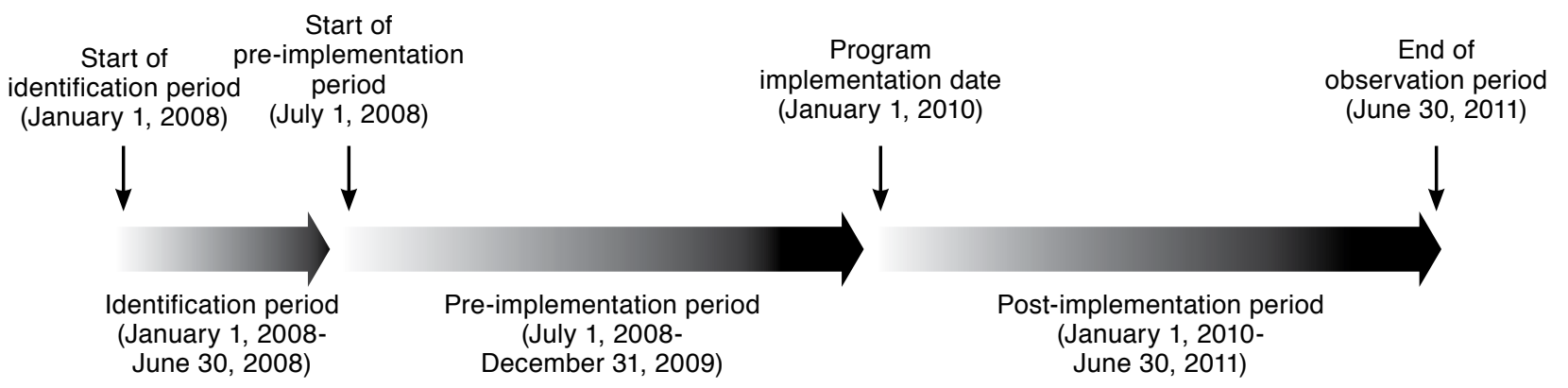

identification period and before the implementation of the program. The post-implementation period was the 18 months after the start of the ZCP program and included rolling enrollment into the ZCP program. Figure 1 depicts the study period broken down into the 3 time periods with accompanying date ranges for each period. The study used a difference-indifference analysis with propensity score matching to examine changes in adherence and cost for diabetes and/or hyperlipidemia medications between the pre-implementation period and the post-implementation period, comparing those who participated in the ZCP program and those who did not. We analyzed the impact of the ZCP program separately for users of antidiabetics and antihyperlipidemics. It was possible that some eligible beneficiaries were users of both classes of medications. In this case, the beneficiary was considered for both analyses.

\section{Beneficiary Selection}

Selection criteria required that beneficiaries (a) were continuously enrolled in benefits during the identification, preimplementation, and post-implementation periods, and (b) had at least 1 brand or generic medication claim for the treatment of diabetes and/or hyperlipidemia during the identification and post-implementation periods (Figure 2). Beneficiaries who enrolled in the program during the post-implementation period were considered "ZCP users," while those who did not enroll during this period were considered "ZCP nonusers." We identified users of medications for each of these conditions by mapping prescription drug claims data to the Medi-Span Generic Product Index (GPI). Beneficiaries who had a prescription drug claim that mapped to GPI 27 "antidiabetics" or GPI 39 "antihyperlipidemics" were considered to be on a medication used to treat these conditions. To identify whether beneficiaries enrolled in the ZCP program during the first 12 months of the post-implementation period, we used a designation in their prescription claims records that indicated enrollment.

\section{Propensity Score Matching}

ZCP users were matched to ZCP nonusers to reduce the effects of self-selection bias. Propensity scoring was used to obtain 1:1 matches of participants and nonparticipant group members using a "greedy" matching algorithm. ${ }^{31,32}$ Propensity scores were obtained by fitting covariates, which included age, gender, comorbidity count, medication class (antidiabetic, antihyperlipidemic, or both), and pre-implementation adherence into a logistic regression model. Comorbidity count reflects the number of unique medical conditions identified for beneficiaries during the identification period (calendar year 2009). Inferred conditions were based on the mapping of prescriptions provided in the Medispan Drug Indications Database, which imputes a diagnosis to a patient based on the specific drugs in the patient's profile. ${ }^{33}$ This algorithm first matched ZCP program participants to nonparticipants on 5 digits of the propensity score. This was repeated for those who did not match using 4 digits of the propensity score and continued down to a 1-digit match.

\section{Outcomes Measures}

Adherence. Medication adherence was measured using proportion of days covered (PDC) and gaps in medication therapy. PDC was calculated as the sum of the days covered divided by 365 (the number of follow-up days), where days covered is based on the fill date and days supply, as indicated in the prescription claim. In the event a patient had a prescription fill for more than 1 drug within the same therapeutic group, causing overlapping fills, overlapping days were included once. ${ }^{34,35}$

Medication Refill Gap. Medication refill gap, which is calculated for refill prescriptions, was the number of days between the assumed depletion date of 1 claim (the claims fill date plus days supply) and the fill date of the next refill. A refill gap of greater than 180 days was interpreted as an indication that the patient had an interruption in the therapy.

Cost. The impact of the ZCP program on pharmacy benefit cost for the payer reflected the net effect of 3 factors: (a) the cost of the waived copays; (b) the cost of induced demand for 


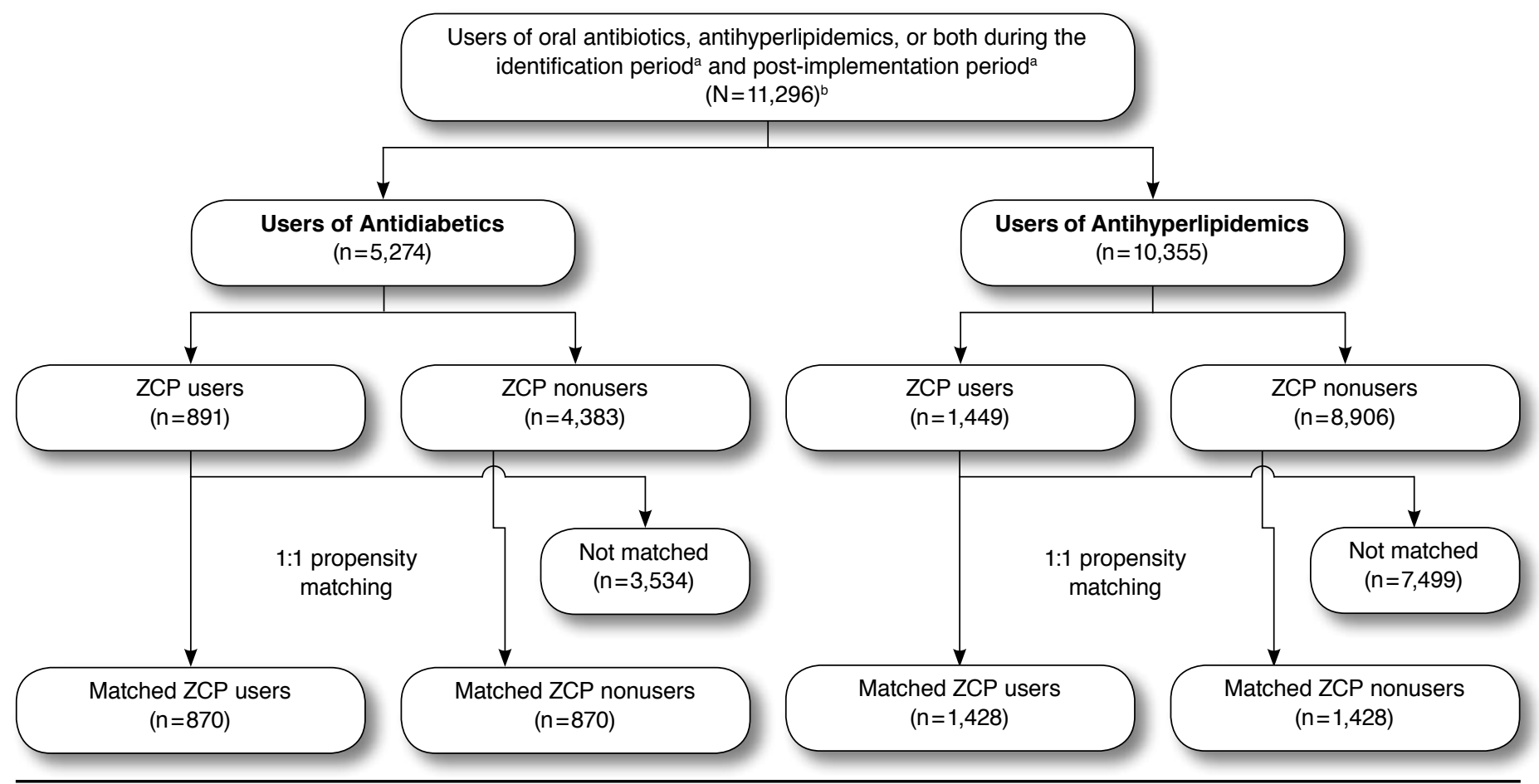

aIdentification period (January 1, 2008, to June 30, 2008); post-implementation period (January 1, 2010, to June 30, 2011).

${ }^{b}$ Count (n) reflects unique beneficiaries using oral antidiabetics, antihyperlipidemics, or both.

$\mathrm{ZCP}=$ zero copay.

generic medications resulting from lower generic copays; and (c) the effect of patients switching from higher copay brand medications to (zero copay) generic medications.

Cost was measured for propensity matched pairs by comparing drug utilization of brand and generic drugs in the targeted medication classes during the pre-implementation period, the post-implementation period, and the change between those 2 periods. The change over time was examined as cost per member per year (PMPY) for the payer as well as the cost change per 30 days of medication for the payer. The PMPY was calculated by summing the cost of medication fills within the specified medication class over the applicable 18-month period and dividing the result by 1.5. To standardize the cost change between beneficiaries, we used a cost change per 30 days of medication. Cost benefit was also examined and formulas for those calculations are included in Table 3.

Statistical Analysis. McNemar's test was used to assess differences between groups for categorical variables and the paired t-test was used to assess differences between groups for continuous variables. The Holm multiple comparison test was to account for multiple comparisons. ${ }^{36}$ All statistical analyses were performed using SAS statistical software, version 9.2 (SAS Institute Inc., Cary, NC).

\section{Results}

There were 5,274 users of antidiabetic medications and 10,355 users of antihyperlipidemic medications who met the eligibility criteria for this study (Figure 2). In all there were 891 users of antidiabetics and 1,449 users of antihyperlipidemics enrolled in the ZCP program during the first 12 months of the postimplementation period. ZCP users and nonusers within each medication class were then matched using 1:1 propensity score matching. There were 21 beneficiaries using antidiabetics and 21 beneficiaries using antihyperlipidemics who enrolled in the ZCP program during the post-implementation period for whom a match could not be found. Thus, these 42 beneficiaries were eliminated from the analysis. The final sample consisted of 870 matched pairs of antidiabetic users and 1,428 matched pairs of antihyperlipidemic users (Figure 2). Table 4 shows baseline characteristics for ZCP users and nonusers within each medication class after matching. There are no statistically significant differences in age, gender, comorbidity count, dual medication class users, or pre-implementation period adherence between matched pairs for either medication class.

Adherence to medication therapy, as measured by PDC, is presented in Table 5 for the matched ZCP users and nonusers within each medication class. Among users of antidiabetics, the 
Evaluation of Increased Adherence and Cost Savings of an Employer Value-Based

Benefits Program Targeting Generic Antihyperlipidemic and Antidiabetic Medications

\section{TABLE 3 Zero Copay Program Cost Benefit Component Work Sheet}

\begin{tabular}{|c|c|c|c|}
\hline Utilization and Cost Component & Antidiabetics & Antihyperlipidemics & Combined \\
\hline PDC a for the comparison group in the baseline period (A) & $81.9 \%$ & $77.6 \%$ & $79.2 \%$ \\
\hline PDC for the comparison group in the post-period (B) & $73.1 \%$ & $70.8 \%$ & $71.7 \%$ \\
\hline PDC for zero copay group in the baseline period (C) & $81.8 \%$ & $77.7 \%$ & $79.3 \%$ \\
\hline PDC for zero copay group in the post-period (D) & $81.9 \%$ & $78.3 \%$ & $79.7 \%$ \\
\hline Estimated PDC for ZCP in the absence of program & $73.0 \%$ & $70.9 \%$ & $71.8 \%$ \\
\hline Converted into 30-day fills equivalent & 8.9 & 8.6 & 8.7 \\
\hline Converted into annual cost based on $\$ 5$ copay per generic $\mathrm{Rx}$ as (bl) & $\$ 44.41$ & $\$ 43.13$ & $\$ 43.67$ \\
\hline Induced demand $(\mathrm{D}-[\mathrm{B} / \mathrm{A}] \times \mathrm{C})$ in $\mathrm{PDC}$ & $8.89 \%$ & $7.41 \%$ & $7.91 \%$ \\
\hline Converted into days supply (E) & 32.4 & 27.0 & 28.9 \\
\hline The cost per generic 30-day script in the intervention period (before copay) (F) & $\$ 9.69$ & $\$ 9.69$ & $\$ 9.69$ \\
\hline Cost of induced demand $([\mathrm{E} / 30] \times \mathrm{F})$ as $(\mathrm{b} 2)$ & $\$ 10.48$ & $\$ 8.73$ & $\$ 9.32$ \\
\hline Total cost due to induced demand (bl+b2) & $\$ 54.89$ & $\$ 51.86$ & $\$ 53.00$ \\
\hline Overall saving of the ZCP program PMPY as (a) & $(\$ 36)$ & $\$ 60$ & $\$ 24$ \\
\hline Net cost benefit of switching from brand to generic $(a+[b 1+b 2])$ & $\$ 18.89$ & $\$ 111.86$ & $\$ 77.00$ \\
\hline
\end{tabular}

Net cost benefit of switching from brand to generic $(a+[b 1+b 2])$

aThe value reflects average PDC for antihyperlipidemic and antidiabetic medications.

$P D C=$ proportion of days covered; $P M P Y=$ per member per year; $R x=$ prescription; $Z C P=$ zero copay.

\section{TABLE 4 Characteristics of Propensity Matched ${ }^{a}$ Zero Copay Users and Nonusers}

\begin{tabular}{|c|c|c|c|c|}
\hline Patient Group & Metric & $\begin{array}{c}\text { ZCP Users } \\
\text { Mean }(95 \% \text { CI })\end{array}$ & $\begin{array}{l}\text { ZCP Nonusers } \\
\text { Mean }(95 \% \text { CI })\end{array}$ & $P$ Value ${ }^{b}$ \\
\hline \multirow{5}{*}{$\begin{array}{l}\text { Antidiabetic users } \\
(\mathrm{n}=1,740)\end{array}$} & Age & $56.0 \quad(55.3,56.7)$ & $56.3 \quad(55.5,57.0)$ & 0.577 \\
\hline & Male gender & $(0.4,0.5)$ & $(0.4,0.5)$ & 1.000 \\
\hline & Comorbidity count $\mathrm{d}^{\mathrm{d}}$ & $(4.1,4.3)$ & $(4.0,4.3)$ & 0.313 \\
\hline & Ratio of patients using both therapy classes & $(0.7,0.8)$ & $(0.7,0.8)$ & 0.860 \\
\hline & Pre-periodc PDC & $(80.3,83.2)$ & $81.9 \quad(80.4,83.3)$ & 0.930 \\
\hline \multirow{5}{*}{$\begin{array}{l}\text { Antihyperlipidemic users } \\
(n=2,856)\end{array}$} & Age & $(56.9,58.0)$ & $(56.5,57.6)$ & 0.298 \\
\hline & Male gender & $(0.5,0.5)$ & $(0.5,0.5)$ & 0.965 \\
\hline & Comorbidity count $^{\mathrm{d}}$ & $(3.7,3.9)$ & $(3.7,3.9)$ & 0.332 \\
\hline & Ratio of patients using both therapy classes & $(0.4,0.4)$ & $(0.4,0.4)$ & 0.321 \\
\hline & Pre-periodc PDC & $(76.5,79.0)$ & $77.6 \quad(76.4,78.8)$ & 0.842 \\
\hline
\end{tabular}

a Propensity score was used to obtain 1:1 matches of ZCP users and nonusers.

${ }^{b}$ No values are statistically significant.

cPre-period reflects the pre-implementation period.

${ }^{d}$ Comorbidity count reflects the number of unique medical conditions identified for beneficiaries during the pre-implementation period.

$C I=$ confidence interval; $P D C=$ proportion of days covered; $Z C P=$ zero copay.

difference in mean PDC between matched ZCP users and nonusers in the pre-period was not significantly different $(81.8 \%$ vs. $81.9 \%, P=0.93)$. The mean difference was significant in the post-period with ZCP users having a significantly higher mean PDC compared with ZCP nonusers $(81.9 \%$ vs. $73.1 \%$, $P<0.001)$. The change between the 2 periods was also significantly different between ZCP users and nonusers, whereby adherence among users remained relatively steady but adherence for nonusers declined ( $0.1 \%$ vs. $-8.8 \%, P<0.001)$. Among users of antihyperlipidemics, there was no significant difference in mean PDC between groups in the pre-period $(77.7 \%$ vs. $77.6 \%, P=0.84$ ); however, there was a significant difference in the post-period between ZCP users and nonusers $(78.3 \%$ vs. $70.8 \%, P<0.001)$. The mean PDC change over time between the antihyperlipidemic ZCP user and nonuser groups was also significant $(0.6 \%$ vs. $-6.8 \%, P<0.001)$ with adherence among users remaining relatively stable and adherence declining in the post-period for nonusers (Table 5).

The proportion of beneficiaries with greater than 180 gap days by ZCP user status is also presented in Table 5. Among antidiabetic users, there was a significant difference in the proportion of beneficiaries with more than 180 gap days between the ZCP users and nonusers in the pre-period (8.3\% vs. $5.5 \%$, $P=0.02)$ and post-period $(10.0 \%$ vs. $19.1 \%, P<0.001)$. The change over time in the ZCP users group was also significantly smaller compared with the ZCP nonusers group, which actually increased substantially in the post-period (1.7\% vs. $13.6 \%$, $P<0.001)$. The proportion of beneficiaries with gap days 
Evaluation of Increased Adherence and Cost Savings of an Employer Value-Based

Benefits Program Targeting Generic Antihyperlipidemic and Antidiabetic Medications

TABLE 5 Pre-implementation and Post-implementation Adherence Measures for Zero Copay Users and Nonusers

\begin{tabular}{|c|c|c|c|c|c|}
\hline Patient Group & Outcomes Metric & $\begin{array}{c}\text { ZCP Users } \\
\text { Mean }(95 \% \text { CI) }\end{array}$ & $\begin{array}{l}\text { ZCP Nonusers } \\
\text { Mean }(95 \% \text { CI })\end{array}$ & $\begin{array}{l}\text { Difference } \\
(95 \% \mathrm{CI})\end{array}$ & $P$ Value ${ }^{c}$ \\
\hline \multirow{6}{*}{$\begin{array}{l}\text { Antidiabetic users } \\
(\mathrm{n}=1,740)\end{array}$} & Pre-period PDCa (A) & $81.8 \quad(80.3,83.2)$ & $81.9 \quad(80.4,83.3)$ & $(1.7,-1.9)$ & 0.930 \\
\hline & Post-period PDC (B) & $81.9 \quad(80.1,83.8)$ & $(71.2,74.9)$ & $(11.3,6.3)$ & $<0.001$ \\
\hline & PDC change (B-A) & $(-1.6,1.9)$ & $(-10.5,-7.0)$ & $(11.4,6.4)$ & $<0.001$ \\
\hline & Pre-period \% with gap ${ }^{b}>180$ days $(C)$ & $(6.6,10.0)$ & $(3.8,7.2)$ & $(5.0,0.5)$ & 0.017 \\
\hline & Post-period \% with gap > 180 days (D) & $(7.7,12.3)$ & $19.1 \quad(16.8,21.4)$ & $-9.1 \quad(-5.9,-12.3)$ & $<0.001$ \\
\hline & Change (D-C) & $(-0.9,4.4)$ & $13.6 \quad(10.9,16.2)$ & $-11.8(-8.2,-15.5)$ & $<0.001$ \\
\hline \multirow{6}{*}{$\begin{array}{l}\text { Antihyperlipidemic } \\
\text { users }(n=2,856)\end{array}$} & Pre-period PDC ${ }^{a}(A)$ & $(76.5,79.0)$ & $77.6 \quad(76.4,78.8)$ & $(1.6,-1.3)$ & 0.842 \\
\hline & Post-period PDC (B) & $(76.9,79.8)$ & $(69.3,72.3)$ & $(9.5,5.5)$ & $<0.001$ \\
\hline & PDC change $(\mathrm{B}-\mathrm{A})$ & $(-0.8,1.9)$ & $(-8.1,-5.4)$ & $(9.2,5.5)$ & $<0.001$ \\
\hline & Pre-period \% with gap > 180 days (C) & $(9.2,12.5)$ & $(9.2,12.4)$ & $(2.3,-2.1)$ & 0.950 \\
\hline & Post-period \% with gap > 180 days (D) & $(10.0,13.9)$ & $(20.1,23.9)$ & $(-7.3,-12.7)$ & $<0.001$ \\
\hline & Change (D-C) & $(-1.1,3.3)$ & $(9.0,13.4)$ & $(-7.0,-13.2)$ & $<0.001$ \\
\hline
\end{tabular}

aPDC indicates the proportion of days in the measurement period "covered" by prescription claims for the same medication or another in its therapeutic category.

b"\% with gap $>180$ days" measures the percentage of patients with a gap greater than 180 days in their medication utilization coverage.

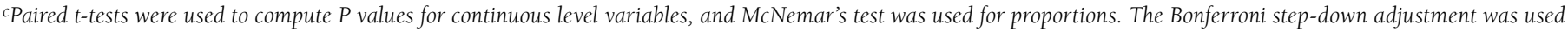
to control the family-wise error rate (FWER). 36

$C I=$ confidence interval; $P D C=$ proportion of days covered; $Z C P=$ zero copay.

TABLE 6 Prescription Utilization Pre-implementation to Post-implementation Trend: Antidiabetic and Antihyperlipidemic Medications

\begin{tabular}{|c|c|c|c|c|c|}
\hline Patient Group & Outcomes Metric & $\begin{array}{c}\text { ZCP Users } \\
\text { Mean (95\% CI) \$ }\end{array}$ & $\begin{array}{c}\text { ZCP Nonusers } \\
\text { Mean }(95 \% \text { CI) \$ }\end{array}$ & $\begin{array}{l}\text { Difference } \\
(95 \% \text { CI }) \$\end{array}$ & $P$ Value $^{b}$ \\
\hline \multirow{4}{*}{$\begin{array}{l}\text { Antidiabetic users } \\
(\mathrm{n}=1,740)\end{array}$} & Pre-period PMPYa (A) & $773 \quad(700,846)$ & $993(920,1,066)$ & $-220 \quad(-117,-323)$ & $<0.001$ \\
\hline & Post-period PMPY (B) & $1,354(1,235,1,472)$ & $1,577(1,458,1,695)$ & $(-57,-389)$ & 0.009 \\
\hline & PMPY change (B-A) & $581 \quad(507,654)$ & $584 \quad(510,657)$ & $(99,-106)$ & 0.951 \\
\hline & Cost change per 30 days supply of Rx & $(1,5)$ & $(8,12)$ & $(-4,-10)$ & $<0.001$ \\
\hline \multirow{4}{*}{$\begin{array}{l}\text { Antihyperlipidemic } \\
\text { users } \\
(n=2,856)\end{array}$} & Pre-period PMPYa (A) & $(200,241)$ & $(326,367)$ & $(-98,-155)$ & $<0.001$ \\
\hline & Post-period PMPY (B) & $(237,304)$ & $(456,523)$ & $(-172,-265)$ & $<0.001$ \\
\hline & PMPY change $(B-A)$ & $(31,70)$ & $(123,163)$ & $(-65,-120)$ & $<0.001$ \\
\hline & Cost change per 30 days supply of Rx & $(-6,-4)$ & $(-1,1)$ & $(-4,-6)$ & $<0.001$ \\
\hline
\end{tabular}

a Refers to count of unique beneficiaries within therapy class.

bPaired t-test was used to assess cost changes.

$C I=$ confidence interval; $P M P Y=$ per member per year; $R x=$ prescription; $Z C P=$ zero copay.

greater than 180 was virtually equal between the antihyperlipidemic ZCP users and nonusers during the pre-period (10.9\% vs. $10.8 \%, P=0.95)$. However, in the post-period and when examining the difference over time (post-period minus preperiod), there was significant difference between the groups (post: $12.0 \%$ vs. $22.0 \%, P<0.001$, change: $1.1 \%$ vs. $11.2 \%$, $P<0.001$; Table 5). Similar to antidiabetics, this metric did not change much over time for ZCP users; however, the proportion of nonusers with a significant gap in days coverage increased significantly in the post-period compared with the pre-period.

Table 6 displays the total cost PMPY incurred by ZCP users and nonusers during the pre-period to the post-period within each medication class. Antidiabetic ZCP users had significantly lower pre- and post-period PMPY costs compared with nonusers (pre-period: $\$ 773$ vs. $\$ 993, P<0.001$; post-period: $\$ 1,354$ vs. $\$ 1,577, P=0.009)$. There was no significant difference in the change pattern in PMPY between antidiabetic ZCP users and nonusers $(P=0.95$; Table 3$)$. However, the cost change per 30 days of medication differed significantly between the 2 groups, whereby ZCP users had a significantly lower rise in cost compared with nonusers ( $\$ 3$ vs. $\$ 10, P<0.001$ ). Among antihyperlipidemics, ZCP users had significantly lower PMPY costs pre- ( $\$ 220$ vs. $\$ 346, P<0.001)$ and post-implementation ( $\$ 271$ vs. $\$ 489, P<0.001$ ). They also had a significantly smaller increase in PMPY over time compared with nonusers (\$51 vs. $\$ 143, P<0.001)$. Furthermore, the cost change per 30 days of medication was significantly lower for ZCP users compared with nonusers ( $\$-5$ vs. $\$ 0, P<0.001$; Table 6).

We further analyzed the sources of gain and loss to the employer from the different effects of the program. We 
estimated the effect of the employer's cost of implementing the ZCP as the sum of 3 components (Table 3): (a) the cost of waiving the $\$ 5$ generic copay; (b) the cost of the induced demand for additional days supply, and (c) the savings due to members switching from brand to generic drugs.

To estimate the cost of the waiver of the $\$ 5$ copay for a 30-day supply, we used the experience of the comparison group to estimate the PDC for all ZCP members in the absence of the program. PDC for the comparison group in the baseline year was 0.792 . The PDC fell to 0.717 in the comparison group in the following year, or a reduction of $9.5 \%$. The baseline PDC in the zero copay group was 0.793 ; the estimated PDC for this group in the absence of the ZCP program was $(0.717 / 0.792) \times$ $(0.793)=0.718$, or 8.7030 -day fills. Thus, we estimated that the cost of the copay waiver (assuming no induced demand) was $\$ 5 \times 8.7$, or $\$ 43.67$ (Table 3).

The cost of induced demand (additional generic drugs dispensed to the ZCP population) represents an increase in cost to the employer. The difference between the expected PDC for the participating group and the actual PDC for this group was $(0.797-0.718)=0.079$. Applying this difference in PDC to 365 days supply, we derived an induced demand for 28.9 additional days supply. The cost per generic 30-day prescription in the intervention period was $\$ 9.69$ before copay. Hence, the estimated cost of the induced demand was $(28.9 / 30.0) \times(\$ 9.69)$ or $\$ 9.32$ (Table 3).

We previously calculated the overall effect of the ZCP program as a net cost reduction of $\$ 24.00$ PMPY. The effect of generic switching is a reduction in the employer's cost, which we estimate as the difference between the net cost reduction of $\$ 24.00$ PMPY and the increase in cost due to the 2 factors above (\$53.00), or \$77.00 PMPY (Table 6).

\section{Discussion}

This VBBD program was an opt-in program consisting of a disease management component with a reduction in medication copayment as an incentive for participation. This study adds to an existing body of literature concerning other VBBD programs that have used an opt-in design with a disease management component using the zero copay mechanism as an incentive. ${ }^{37-41}$ However, this program was unique from other published opt-in studies because it only lowered the copayment for generic medications used to treat the 2 conditions as an incentive. The other opt-in studies did not specify that they restricted the copayment reduction to a specific medication type (i.e., generic only). ${ }^{37-41}$

This ZCP program achieved an enrollment rate of $17 \%$ among eligible beneficiaries taking antidiabetic medications and $14 \%$ among eligible beneficiaries taking antihyperlipidemic medications during the first 12 months of the 18-month post-implementation period. This is a smaller proportion than the only other study we found that included enrollment statistics, The Asheville Project. The Asheville Project's diabetes management program enrolled $43 \%$ of those eligible for the program with a similar time frame. ${ }^{41}$ It is possible that a higher proportion enrolled in The Asheville Project because of the incentives it provided. For example, the project provided persons that opted into the program a free glucometer and waived copayments for diabetic supplies. Furthermore, to our knowledge, all diabetes medications were eligible for copayment reductions, not just generic medications. ${ }^{41}$

The current study found a PDC change for ZCP users of 0.1 percentage points for antidiabetics and an increase of 0.6 percentage points in antihyperlipidemics from pre- to postimplementation of the ZCP program. Two other studies that examined a 1-year change in adherence after implementation of the VBBD program targeting medications for chronic conditions found increases in adherence ranging from 0.94.0 percentage points. ${ }^{17,42}$ However, the design of the other studies differed from the current study in several ways. First, these studies did not include an opt-in process-beneficiaries received the benefits of the program without an enrollment process. Furthermore, they did not limit the reduction in copayment exclusively for generic medications and did not require participation in a disease management program. ${ }^{17,42} \mathrm{It}$ should also be noted that these comparison studies used medical possession ratio, as opposed to PDC, to measure adherence. Taken together, the differences in study design and measurement between previous studies and the current study limit our ability to draw any conclusions based on the differences found.

Perhaps the most striking result of this study was the impact of participation on adherence between ZCP users and nonusers. Among ZCP users, the program appeared to sustain the preimplementation adherence rate into the post-implementation period, whereas the adherence rate for the nonusers declined in the post-implementation period. This result suggests that the program may serve to prevent reductions in adherence over time. Another study found similar results. A retrospective prepost study conducted by Choudhry et al. (2010) evaluated the impact of a VBBD program that reduced the copay for statins and a medication to treat clotting disorders ${ }^{16}$ This study found that the VBBD program served to prevent the decline in adherence post-implementation for the intervention beneficiaries, while adherence for the comparison group continued to decline in the post-implementation period. ${ }^{16}$ Furthermore, our study found through the difference-in-difference analysis that the percentage of change over time differed between ZCP users and nonusers for both medication classes, with a more positive adherence among ZCP users relative to nonusers. Other VBID studies with a difference-in-difference study design have reported similar results. ${ }^{16-18,30,43-45}$

Even with the increase in mean per-beneficiary prescription cost for the payer after the implementation of the program for both participants and nonparticipants, the increase was generally smaller for participants and statistically smaller among ZCP users of antihyperlipidemics compared with nonusers. 
Furthermore, the mean per-beneficiary cost change from preto post-implementation per 30 days of medication for the payer was significantly smaller when comparing the ZCP users in both classes with nonusers. In fact, for antihyperlipidemics, ZCP users saw a decrease in mean per-beneficiary 30-day medication cost over time. Other studies have generally found VBID programs to either be cost neutral or to provide modest savings for payers, although the costs being measured and methods of measurement varied across studies. ${ }^{37,40,45,46}$

\section{Limitations}

Given that beneficiaries could enroll in the program during the first 12 months of the post-implementation period, it is possible that the amount of time during the post-implementation period when a beneficiary was a ZCP user could have varied. The effect of this limitation is likely to bias results toward the null and lead to a conservative estimate of findings between the ZCP users and nonusers. While program users and nonusers were propensity matched, there were factors that we were not able to control. For example, ZCP users may have been more willing to change from a brand name to a generic equivalent or more likely to have already been on a generic medication prior to program implementation. In addition, due to the limitations of the data (limited variables), it was not possible to adjust for all potential predictors of adherence, such as socioeconomic factors. We also only examined one aspect of cost, namely prescription drug costs. It is possible that the economic effects of positive impact on adherence reach beyond these savings to savings in other medical and productivity costs, which were not examined in the current study. Finally, we were unable to determine if it was the reduction in copay or the disease management program, or both, that accounted for the sustained adherence among participants over time.

\section{Conclusions}

This VBBD program (case management/wellness program combined with the zero copay incentive) had the intended effect of positively impacting adherence to medications used to treat diabetes and high cholesterol for program participants compared with nonparticipants. This difference was mostly via a sustained adherence level among participants in the postimplementation period compared with a decline in adherence among nonparticipants. The program was also associated with a relative cost savings for payers among participants compared with nonparticipants, even though adherence (i.e., prescription drug utilization) among participants was higher compared with nonparticipants. Given the low rate of enrollment into the program, an analysis of reasons for low participation rates is warranted. It is possible that with a higher rate of enrollment, the project's effects could be even more far-reaching.

\section{Authors}

BOBBY CLARK, PhD, MSPharm, MHA, MS, MA, is Director; JANEEN DUCHANE, PhD, MRP, is Senior Director; JOHN HOU, $\mathrm{PhD}$, is Manager; and IAN DUNCAN, FSA, FIA, FCIA, MAAA, is Vice President, Clinical Outcomes \& Analytics, Walgreens Co., Deerfield, Illinois. JENNIFER MCMURRAY, PharmD, is Director, Healthcare Products and Services, Walgreens Co., Deerfield, Illinois, and ELAN RUBINSTEIN, PharmD, MPH, is Principal, EB Rubinstein Associates, Oak Park, California.

AUTHOR CORRESPONDENCE: BOBBY CLARK, PhD, MSPharm, MHA, MS, MA, Director, Clinical Outcomes \& Analytics, Walgreen Co., 1415 Lake Cook Rd., MS \#L444, Deerfield, IL 60015. Tel.: 847.964.6515; E-mail: bobby.clarke@Walgreens.com.

\section{DISCLOSURES}

All authors except Rubinstein are paid employees of Walgreens Co. Rubinstein is a paid consultant to Walgreens Co.

Clark, Hou, and Duncan were responsible for concept and design and data interpretation. McMurray was responsible for data collection. Clark, DuChane, Rubinstein, and Duncan wrote the manuscript, and Clark, DuChane, and Hou revised the manuscript.

\section{REFERENCES}

1. Houy M. Value-based benefit design: a purchaser guide. National Business Coalition on Health. January 2009. Available at: http://www. nbch.org/NBCH/files/ccLibraryFiles/Filename/000000000222/VBBD\%20 Purchaser\%20Guide.pdf. Accessed July 22, 2013.

2. Fendrick AM, Chernew ME. Value-based insurance design: a "clinically sensitive, fiscally responsible" approach to mitigate the adverse clinical effects of high-deductible consumer-directed health plans. J Gen Intern Med. 2007;22(6):890-91.

3. Choudhry NK, Rosenthal MB, Milstein A. Assessing the evidence for value-based insurance design. Health Aff (Millwood). 2010;29(11):1988-94.

4. Mahoney JJ. Reducing patient drug acquisition costs can lower diabetes health claims. Am J Manag Care. 2005;11(5 Suppl):S170-76.

5. Sinclair J. Mercer's national survey of employer-sponsored health plans 2010. February 16, 2011. Available at: http://www.ehpco.com/documents/ MercerNationalSurveyResults2010CentralOH.pdf. Accessed July 22, 2013.

6. Yeaw J, Benner JS, Walt JG, Sian S, Smith DB. Comparing adherence and persistence across 6 chronic medication classes. J Manag Care Pharm. 2009;15(9):728-40. Available at: http://www.amcp.org/WorkArea/ DownloadAsset.aspx?id=8250.

7. National Council on Patient Information and Education. Enhancing prescription medicine adherence: a national action plan. August 2007. Available at: http://www.talkaboutrx.org/documents/enhancing_prescription_medicine_adherence.pdf. Accessed July 22, 2013.

8. New England Healthcare Institute. Thinking outside the pillbox: a system-wide approach to improving patient medication adherence for chronic disease. NEHI Research brief. August 2009. Available at: http://www. nehi.net/publications/44/thinking_outside_the_pillbox_a_systemwide_ approach_to_improving_patient_medication_adherence_for_chronic_disease. Accessed July 22, 2013.

9. Chernew M, Gibson TB, Yu-Isenberg K, Sokol MC, Rosen AB, Fendrick AM. Effects of increased patient cost sharing on socioeconomic disparities in health care. J Gen Intern Med. 2008;23(8):1131-36. 
10. Pedan A, Varasteh L, Schneeweiss S. Analysis of factors associated with statin adherence in a hierarchical model considering physician, pharmacy, patient, and prescription characteristics. J Manag Care Pharm. 2007;13(6):487-96. Available at: http://www.amcp.org/WorkArea/ DownloadAsset.aspx?id=7639.

11. Krousel-Wood MA, Muntner P, Islam T, Morisky DE, Webber LS. Barriers to and determinants of medication adherence in hypertension management: perspective of the cohort study of medication adherence among older adults. Med Clin North Am. 2009;93(3):753-69.

12. Osterberg L, Blaschke T. Adherence to medication. N Engl J Med. 2005;353(5):487-97.

13. Gellad WF, Grenard J, McGlynn EA. A review of barriers to medication adherence: a framework for driving policy options. RAND Health. 2009. Available at: http://www.rand.org/content/dam/rand/pubs/technical_reports/2009/RAND_TR765.pdf. Accessed August 4, 2013

14. RAND Health. Health insurance experiment: a classic RAND study speaks to the current health care reform debate. Research highlights. 2006. Available at: http://www.rand.org/pubs/research_briefs/2006/RAND_ RB9174.pdf. Accessed August 4, 2013.

15. Doshi JA, Zhu J, Lee BY, Kimmel SE, Volpp KG. Impact of a prescription copayment increase on lipid-lowering medication adherence in veterans.

Circulation. 2009;119(3):390-97.

16. Choudhry NK, Fischer MA, Avorn J, et al. At Pitney Bowes, value-based insurance design cut copayments and increased drug adherence. Health Aff (Millwood). 2010;29(11):1995-2001.

17. Chernew ME, Shah MR, Wegh A, et al. Impact of decreasing copayments on medication adherence within a disease management environment. Health Aff (Millwood). 2008;27(1):103-12.

18. Maciejewski ML, Farley JF, Parker J, Wansink D. Copayment reductions generate greater medication adherence in targeted patients. Health Aff (Millwood). 2010;29(11):2002-08.

19. Solomon MD, Goldman DP, Joyce GF, Escarce JJ. Cost sharing and the initiation of drug therapy for the chronically ill. Arch Intern Med. 2009;169(8):740-48; discussion 748-49.

20. Hunt S, Maerki S, Rosenberg W. Assessing quality-based benefit design. Pacific Business Group on Health and California Healthcare Foundation. April 2006. Available at: http://www.pbgh.org/storage/documents/reports/ PBGH-CHCFQualityBenDesignPWC-04-2006.pdf. Accessed July 22, 2013.

21. Gibson TB, Mark TL, McGuigan KA, Axelsen K, Wang S. The effects of prescription drug copayments on statin adherence. Am J Manag Care. 2006;12(9):509-17.

22. Hovinga CA, Asato MR, Manjunath R, et al. Association of nonadherence to antiepileptic drugs and seizures, quality of life, and productivity: survey of patients with epilepsy and physicians. Epilepsy Behav. 2008;13(2):316-22

23. Cerghet M, Dobie E, Lafata JE, et al. Adherence to disease-modifying agents and association with quality of life among patients with relapsingremitting multiple sclerosis. Int J MS Care. 2010;12(2):51-58.

24. Halpern R, Becker L, Iqbal SU, Kazis LE, Macarios D, Badamgarav E. The association of adherence to osteoporosis therapies with fracture, allcause medical costs, and all-cause hospitalizations: a retrospective claims analysis of female health plan enrollees with osteoporosis. J Manag Care Pharm. 2011;17(1):25-39. Available at: http://www.amcp.org/WorkArea/ DownloadAsset. aspx?id=8963.

25. Roebuck MC, Liberman JN, Gemmill-Toyama M, Brennan TA. Medication adherence leads to lower health care use and costs despite increased drug spending. Health Aff (Millwood). 2011;30(1):91-99.

26. Ho PM, Rumsfeld JS, Masoudi FA, et al. Effect of medication nonadherence on hospitalization and mortality among patients with diabetes mellitus. Arch Intern Med. 2006;166(17):1836-41.
27. Pladevall M, Williams LK, Potts LA, Divine G, Xi H, Lafata JE. Clinical outcomes and adherence to medications measured by claims data in patients with diabetes. Diabetes Care. 2004;27(12):2800-05.

28. Gibson TB, Mark TL, Axelsen K, Baser O, Rublee DA, McGuigan KA. Impact of statin copayments on adherence and medical care utilization and expenditures. Am J Manag Care. 2006;12(Spec no.): SP11-S19.

29. Fairman KA, Curtiss FR. What do we really know about VBID? Quality of the evidence and ethical considerations for health plan sponsors.

J Manag Care Pharm. 2011;17(2):156-74. Available at: http://www.amcp.org/ WorkArea/DownloadAsset.aspx?id=8984.

30. Chang A, Liberman JN, Coulen C, Berger JE, Brennan TA. Value-based insurance design and antidiabetic medication adherence. Am J Pharm Benefits. 2010;2(1):39-45.

31. Parsons LS. Reducing bias in a propensity score matched-pair sample using greedy matching techniques. Paper presented at: 2001 SAS Global Forum; April 22-25, 2001; Long Beach, CA.

32. Rosenbaum PR, Rubin DB. The central role of the propensity score in observational studies for causal effects. Biometrika. 1983;70(1):41-55.

33. Wolters Kluwer Health Inc. Drug Indications Database documentation manual. December 2007. Available at: http://www.medi-span.com/drugindications-database.aspx. Accessed July 22, 2013.

34. Leslie R. Using arrays to calculate medication utilization. Paper presented at: 2007 SAS Global Forum; April 16-19, 2007; Orlando, FL.

35. Choudhry NK, Shrank WH, Levin RL, et al. Measuring concurrent adherence to multiple related medications. Am J Manag Care. 2009;15(7):457-64.

36. Holm S. A simple sequentially rejective multiple test procedure. Scand J Statist. 1979;6(2):65-70

37. Fera T, Bluml BM, Ellis WM. Diabetes Ten City Challenge: final economic and clinical results. J Am Pharm Assoc. 2009;49(3):383-91.

38. Bunting BA, Smith BH, Sutherland SE. The Asheville Project: clinical and economic outcomes of a community-based long-term medication therapy management program for hypertension and dyslipidemia. J Am Pharm Assoc. 2008;48(1):23-31.

39. Bunting BA, Cranor CW. The Asheville Project: long-term clinical, humanistic, and economic outcomes of a community-based medication therapy management program for asthma. J Am Pharm Assoc. 2006;46(2):133-47. 40. Cranor CW, Bunting BA, Christensen DB. The Asheville Project: longterm clinical and economic outcomes of a community pharmacy diabetes care program. J Am Pharm Assoc. 2003;43(2):173-84.

41. Cranor CW, Christensen DB. The Asheville Project: short-term outcomes of a community pharmacy diabetes care program. J Am Pharm Assoc (Wash). 2003;43(2): 149-59.

42. Farley JF, Wansink D, Lindquist JH, Parker JC, Maciejewski ML. Medication adherence changes following value-based insurance design. Am J Manag Care. May 2012;18(5):265-74.

43. Frank MB, Fendrick AM, He Y, et al. The effect of a large regional health plan's value-based insurance design program on statin use. Med Care. 2012;50(11):934-39.

44. Zeng F, An JJ, Scully R, Barrington C, Patel BV, Nichol MB. The impact of value-based benefit design on adherence to diabetes medications: a propensity score-weighted difference in difference evaluation. Value Health. 2010;13(6):846-52.

45. Gibson TB, Wang S, Kelly E, et al. A value-based insurance design program at a large company boosted medication adherence for employees with chronic illnesses. Health Aff (Millwood). 2011;30(1):109-17.

46. Garrett DG, Bluml BM. Patient self-management program for diabetes: first-year clinical, humanistic, and economic outcomes. J Am Pharm Assoc (2003). 2005;45(2):130-37. 